and constant boiling point which contains about two per cent methane.

If we use the constant litre weight found by Gonzalez, 1.5363, and the results of Patterson, WhytlawGray, and Cawood at $21^{\circ}$, to calculate the coefficient of thermal expansion of methyl fluoride, we get the normal value 0.0037 . On the other hand, van Laar, ${ }^{10}$ with the critical constants as determined by Collie with the impure gas, has calculated the compressibility coefficient 1.0094, which approaches the value deduced by Patterson, Whytlaw-Gray, and Cawood, namely, $1 \cdot 0109$. It seems very probable that the methyl fluoride used by the latter workers was contaminated with some two per cent of methane.

It appears to be highly improbable that the atomic weight of fluorine should exceed 19.000. A detailed paper will appear soon elsewhere. E. MoLes.

National Institute of Physics and Chemistry, University, Madrid,

$$
\text { Oct. } 15 \text {. }
$$

1 Nature, 128, 375, Aug. 29, 1931.

2 Jour. Am. Chem. Soc., 34, 592; 1912.

3 Carnegie Institution, Report No. 267, p. 47 ; 1918.

4 Jour. Phys. Chem., 21, 81; 1917.

" "Recalculations on Atomic Weights", 4th edition, pp. 273 and 315

8 Jour. Chim. Phys., 11, pp. 1 and $273 ; 1913$.

7 Jour. Chim. Phys., 18, p. 353; 1920.

8 Proc. Roy. Soc., A, 115, p. 503; 1927 .

- Anales Soc esp Fis. Quim, 20, 539; 1922.

10 "Zustandsgleichung", p. 46.

\section{Respiration of Healthy and Leaf Roll Potatoes.}

IN the study of virus diseases of plants, comparatively little attention seems to have been paid to the effect on metabolism. This is particularly surprising in the case of potato leaf roll where the retardation in growth, pallor of the foliage, and the accumulation of carbohydrates in the leaves at the expense of the tubers, point to the disease effecting profound changes in normal metabolism. In the belief that this modified metabolism would be reflected in the rate of respiration, a comparative study of the respiration (as measured by the weight of carbon dioxide evolved per gram fresh weight and dry weight) of healthy and leaf roll potatoes has been made at various stages in the life-cycle.

Briefly, the work has shown that the respiration of the immature healthy tuber is higher than on maturation in storage, and again rises with the development of sprouts. On the first unfolding of the leaves there is an enormous rise in the respiration rate, followed by a gradual, though slight, fall as new tubers are produced. The eycle of events is much the same in the infected potato, but with important differences in detail. The infected immature tuber respires at a higher rate than the healthy tuber when first lifted, then falling, on storage, to a level slightly below that of the healthy mature tuber. On sprouting, the respiration rate lags behind that of the healthy tuber until the sprouts break into leaf, when the great increase in carbon dioxide production noted in the healthy plant is exceeded by the diseased one. This higher rate of respiration of infected foliage is evident, therefore, before any rolling or excess accumulation of starch occurs in the leaves, but not necessarily before sugars begin to accumulate. It remains at a higher level than the respiration of the healthy plant during the rest of the growing period. It is of interest to recall that Thung, though mainly working with detached leaves floating on water, also found a higher rate of respiration in leaf roll than in healthy leaves.

Anaerobic respiration in nitrogen is unaffected by the virus ; the tuber-whether diseased or notproducing $70-80$ per cent of the carbon dioxide evolved under aerobic conditions. The growing plant is able to emit as much carbon dioxide anaerobically as it does aerobically, whether infected or healthy. The changes in respiration during the life of a potato could therefore be represented by much the same curve for anaerobic as for aerobic conditions. It is higher in the diseased immature tubers, about the same in diseased and healthy after prolonged storage, lower in diseased sprouting tubers, but much higher than the healthy plant once leaves have developed.

Glasshouse plants growing in pots have been used throughout this work, whilst tubers in different stages of maturity have been obtained from plants growing under normal field conditions. No explanation of these results can be offered at present, but it is hoped that further studies will not only throw some light on the nature of the metabolic disturbances caused by the leaf roll virus, but also provide a new angle from which to view the inter-relationship of respiration, available respirable material, and growth in normal plants.

University College of North Wales, T. WHITEHEAD. Bangor, Nov. 6.

\section{Eurytemora thompsoni, A. Willey : A New European Record.}

IT is a common, but none the less mistaken, conception that the be-all and end-all of the systematist is the discovery of new species. In reality, the discovery of well-known species in remote parts of the world has a far greater fascination and is infinitely more important. It is perhaps no exaggeration to state that the world-wide distribution of common species of animals and plants is the basis of one of the most fundamental conceptions of the whole of the science of biology, since on it rests almost our only data for observing the influence of environment.

In June of the present year, on visiting a brackishwater pool, removed but not far distant from the sea at South Lancing, Sussex, I came across numerous specimens of a species of Eurytemora, a well-known genus of copepod.

Close investigation showed that the species was not British or even European, and it was, in fact, Eurytemora thompsoni, Willey, of which no other record existed beyond that of Prof. Arthur Willey, of McGill University, who took it from the stomach of a fish caught in a weir near the low-tide level at Scotsman Bay, Nova Scotia.

The species had also been found, but not recorded so far, by Prof. Smirnov, of Leningrad, in the brackish waters of the Sea of Okhotsk. A truly remarkable distribution as it stands, but it is more than likely that the species exists in many other brackish-water localities, but so far it has escaped detection.

A full description of the species has just been published in the November part of Annals and Magazine of Natural History

Marlborough College,

Wilts, Nov. 14.

A. G. Lowndes.

\section{Uteroverdin.}

ONE of us ${ }^{1}$ has recently isolated oocyan - the bluegreen pigment of the shells of many birds' eggs-and characterised it as an ether-soluble pyrrol pigment closely related to the bile pigments. We have now found a second example of this class of substances in the green pigment of the dog's placenta, the properties of which are very similar to those of oocyan. This pigment was examined in 1871 by Etti, ${ }^{2}$ and considered to be biliverdin; it is formed by the transformation of the blood-pigment in the extravasates of the dog's placenta. ${ }^{3}$ While the methoxyl content 